\title{
EFFECT OF WHEAT BRAN SUBSTITUTION FOR CORN AND DEHYDRATED ALFALFA ON FINISHING LAMBS
}

\author{
M. S. Islam ${ }^{1}$, M. Khan ${ }^{2}$ and A. Reza ${ }^{3}$
}

\begin{abstract}
Two trials with finishing lambs were conducted to study the effect of substituting wheat bran for either dehydrated alfalfa pellets or corn. In trial 1, the basal ration fed to lambs was compared by replacing dehydrated alfalfa $(12.5 \%)$ with wheat bran. Growth responses to wheat bran or dehydrated alfalfa were not different $(P>0.74)$. In trial 2, thirty-two lambs were blocked by weight and randomly assigned to four treatments consisting of the basal ration plus three different levels of wheat bran $(22 \%, 46 \%$ and $68 \%)$ substituted for corn. The results indicated that animals on the control diet (without wheat bran) performed better $(\alpha=0.5)$ than the three wheat bran diets, where the two lowest level of wheat bran diet either maintained or gained weight. Animals on the highest level of wheat bran lost weight. Gain response to the corn diet was higher $(P<0.25$ and $P<0.003)$ than $22 \%$ and $46 \%$ wheat bran supplemented diets. Results also indicated that diet- $A$ (control) and diet-C (46\% wheat bran) had similar DM digestibilities, where as the diet-B (22\% wheat bran) gave higher digestibilities for DM, ADF and NDF. ADF digestibility was very low in control diet $(A)$ as compared to diet-B (22\% wheat bran) and diet-C (46\% wheat bran) because the control diet contained little fiber. Higher protein digestibility was observed in diet-A. Although, diet-B performed better than diet-C, Performance of diet-B was not parallel to that of diet-A and difference between diet$B$ and diet-C was not statistically significant $(P>0.05)$.
\end{abstract}

Key words: Finishing lambs, Digestion trial, Wheat bran, Growth performance

\section{Introduction}

Concentrate feeds that supply both protein and energy are important considerations for livestock production. In many situations, availability of concentrate feed is challenged. Therefore, economics have driven producers to explore the possibilities alternatives to the traditional protein and energy supplements. As a result, interest in feedstuff byproducts, such as wheat bran, corn gluten feed, corn bran, wheat middlings, soybean hulls, oat hulls and even rice hulls. These supplements are often low to moderate in their crude protein and high in fiber content.

It has been postulated by researchers that using low-strach and high-fiber feedstuffs could eliminate the negative effects of grain based supplements (Fleck et al., 1988;

\footnotetext{
${ }^{1}$ Department of Animal Science and Industry, Kansas State University, Kansas, USA

2 Department of Animal Science, Bangladesh Agricultural University, Mymensingh-2202, Bangladesh

${ }^{3}$ Department of Animal Nutrition, Bangladesh Agricultural University, Mymensingh-2202, Bangladesh
}

(Received: August 02, 2009) 
Oliveros et al., 1989) probably by avoiding $\mathrm{pH}$ depression characteristics of cereal grain supplementations. With this in view, the present study was designed to determine the effect of wheat bran on finishing lambs.

Wheat bran, which consists almost entirely of the coarse outer coating of the wheat kernel, is one of the important livestock feeds (Morrison, 1961). Wheat bran is quite palatable, and is well known for its ability to prevent constipation because of its swelling and water-holding capacities. Bran has a high capacity to absorb water and swell, because of its fiber and non-starch carbohydrates (e.g., glucans). So it has a bulk effect in the colon, giving it laxative properties (Cheeke, 1991). Wheat bran averages 17\% crude protein, $4.5 \%$ fat and has $70 \%$ of TDN, which is slightly less than oats (Preston, 2006). In many countries, especially in the developing regions of the world, wheat bran and similar feedstuffs are the main energy supplements for livestock. In Bangladesh, for instance, wheat bran is very popular but an expensive livestock feed. People always count on it, and to minimize the cost of energy and protein supplement substitute rice bran or hulls for wheat bran. It seems to be an important livestock feed around the world. Surprisingly, little information is available regarding wheat in ruminant nutrition in the United States. It would appear that the reluctance to use wheat by-products in this country is because of sufficient supply of low cost corn and soybean. However, when common feedstuffs such as corn and soybean are expensive or unavailable due to crop failures, wheat bran could serve as a major stock feed. Therefore, it was necessary to explore the possibilities of using wheat bran in small ruminant feeding as an alternate feedstuff. Therefore, corn and dehydrated alfalfa in Kansas State University (KSU) formulated rations were replaced at different levels by wheat bran to observe the effects on finishing lambs.

\section{Materials and Methods}

The whole experiment was divided into Trial 1 and Trial 2. In Trial 1 sixty lambs, weighing an average of $33 \mathrm{~kg}$, were randomly allotted to 4 groups. They were housed in pens $(4.6 \times 15.25 \mathrm{~m}), 15$ in each pen. Animals were kept without feed and water for 24 hours and then weighed on two consecutive days before starting the trial. The basal diet (Table 1) was composed of $64 \%$ corn, $25 \%$ dehydrated alfalfa. Fifty per cent of the dehydrated alfalfa in the diet was replaced by wheat bran. Two rations, the basal (control) and the treatment (12.5\% wheat bran) were replicated once. The diets were isocaloric and met the NRC requirements (NRC, 1985) of finishing lambs. The animals were fed twice daily for an 8 week period. On average, $1.5 \mathrm{~kg}$ feed was given to each animal daily. Fresh feed was offered daily and the refusals were collected and weighed. Orts (refusals) were assumed to be equivalent to fresh feed, because very little sorting was observed. To obtain intake parameter, orts were subtracted from the feed. All animals had free access to fresh water.

Trial 2 was conducted for a 4 week period. Thirty-two lambs were blocked by weight, the average of which was $54 \mathrm{~kg}$, and randomly assigned to 4 treatments to evaluate the 
effects of wheat bran on finishing lambs when supplemented at different levels to a corn diet.

The treatments were:

1. Control- without wheat bran (A)

2. $22 \%$ wheat bran (B)

3. $46 \%$ wheat bran (C)

4. $68 \%$ wheat bran (D)

Table 1. Ingredient and nutrient composition of rations fed to sheep (Experiment 1)

\begin{tabular}{|l|c|c|}
\hline \multirow{2}{*}{ Parameters } & \multicolumn{2}{|c|}{ Diets $^{\#}$} \\
\cline { 2 - 3 } Ingredient composition (\%) & A & B \\
Corn & & \\
Dehy. Alfalfa & 63.87 & 63.87 \\
Wheat bran & 25.00 & 12.50 \\
SBM & - & 12.50 \\
Limestone & 4.63 & 4.63 \\
Stock salt & 0.85 & 0.85 \\
AMM SO 4 & 1.00 & 1.00 \\
Bovatec & 0.50 & 0.50 \\
Vit. A 3000 & 0.20 & 0.20 \\
Vit. D 1600 & 0.02 & 0.02 \\
Vit. E 44 & 0.01 & 0.01 \\
Selenium & 0.05 & 0.05 \\
Wet Molasses & 0.05 & 0.05 \\
Nutrient Composition & 4.00 & 4.00 \\
CP (\%) & & \\
NDF (\%) & 14.73 & 14.57 \\
ADF (\%) & 36.19 & 29.84 \\
ME, MCal/kg & & 6.29 \\
\hline
\end{tabular}

${ }^{\#} \mathrm{~A}=$ Control diet (without wheat bran), $\mathrm{B}=$ Treatment diet (Bran diet)

${ }^{1}=$ Calculated from NRC (1985) values

Each group was housed in a $4.6 \times 15.25 \mathrm{~m}$ pen. Feed was supplied twice daily at 7 am and $5 \mathrm{pm}$. The orts were collected, weighed and recorded and subtracted from the supplied feed to get the intake parameters. All animals had free access to fresh water. At the end of the trial, final weights of individual animals were recorded and compared with that of the initial weight in the different rations.

In Trial 2, animal performance in terms of weight gain in different treatment groups were compared with that of control diet (without wheat bran) using the t-test. The value for the t-test with 14 degrees of freedom was obtained from Table 2 in the Appendix (Ott, 1984) that shows the calculated t-values $(5.56,4.72,4.19)$ are greater than the tabulated 
Bang. J. Anim. Sci. 2009, 38(1\&2)

(1.76) value, which concludes diet- $A$ (control) performed better $(\alpha=0.05)$ than treatment diets (diet B, C and D).

Table 2. Basal rations with increasing levels of wheat bran substituted for corn fed to finishing lambs (Experiment 2)

\begin{tabular}{|l|c|c|c|c|}
\hline \multirow{2}{*}{$\begin{array}{c}\text { Item } \\
\text { Ingredient, \%) }\end{array}$} & \multicolumn{4}{c|}{ Diets $^{\#}$} \\
\cline { 2 - 5 } & A & B & C & D \\
\hline Corn & 63.85 & 45.50 & 22.16 & -- \\
Wheat bran & -- & 22.20 & 46.16 & 67.59 \\
SBM & 4.65 & 1.05 & -- & -- \\
Dehy. Alfalfa & 25.00 & 25.00 & 25.00 & 25.00 \\
Limestone & 0.85 & 0.60 & 1.03 & 1.77 \\
Stock salt & 1.00 & 1.00 & 1.00 & 1.00 \\
AMM SO & 0.50 & 0.50 & 0.50 & 0.50 \\
Bovatec & 0.02 & 0.02 & 0.02 & 0.02 \\
Vit. A 3000 & 0.02 & 0.02 & 0.02 & 0.02 \\
Vit. D 1600 & 0.01 & 0.01 & 0.01 & 0.01 \\
Vit. E 44 & 0.05 & 0.05 & 0.05 & 0.05 \\
Selenium & 0.05 & 0.05 & 0.05 & 0.05 \\
Wet Molasses & 4.0 & 4.0 & 4.0 & 4.0 \\
\hline
\end{tabular}

\# $A=$ Control diet (without wheat bran), $B=22 \%$ wheat bran supplement diet, $C=46 \%$ wheat bran supplement diet, $\mathrm{D}=68 \%$ wheat bran supplement diet

\section{Statistical analysis}

In Trial 1, animal performance data were analysed as a completely randomized design. Statistical analyses of the experiment were performed using the GLM procedure of SAS (SAS, 1988). The result has interpreted using LSMEANS statement as follows, where A (control) and $B$ (treatment) are statistically insignificant due to $P$ value $(P>0.741)$.

\section{Results and Discussion}

Dehydrated alfalfa $(25 \%)$ in the basal ration (Table 1 ) was replaced by $12.5 \%$ wheat bran to form a treatment diet, both of which were replicated twice. Sixty animals of same size (by weight) and sex were group fed (15 in each pen) for two diets for 60 days. The growth data (Table 3) from both groups indicated similar performance in terms of weight gain in finishing lambs. Data shows that the animals responded to a similar average daily gain in both groups with slightly higher DM intake in basal diet (diet-A, control). The differences between the two diets are statistically insignificant $(P>0.741)$. This result may be interpreted that almost similar function is served by wheat bran when compared with that of dehydrated alfalfa pellets at the level of $12.5 \%$.

Good quality alfalfa has approximately $16 \%$ crude protein, $28 \%$ ADF and 38\% NDF, higher in protein and lower the fiber fractions, the better the quality (Cheeke 1991). 
Wheat bran averages $16.4 \%$ crude protein, 4.5\% fat and has 66.9 lbs of TDN per 100 Ibs. wheat bran is high in phosphorus (1.29\%) and low in calcium (0.13\%). It is rich in niacin and fairly high in thiamin. Wheat bran is equally important for all classes of livestock (Morrison, 1961).

Table 3. Performance of lambs fed a corn-based diet partially substituted for dehydrated alfalfa pellets with wheat bran (Experiment 1)

\begin{tabular}{|l|c|c|c|}
\hline \multirow{2}{*}{ Items } & \multicolumn{2}{|c|}{ Diets $^{\#}$} & \multirow{2}{*}{ SE } \\
\cline { 2 - 3 } & A & B & \\
Weight (kg/head) & & & 0.04 \\
Initial & 33.54 & 33.48 & 0.04 \\
Final & 49.70 & 49.79 & - \\
Daily gain, $\mathrm{kg}$ & 0.29 & 0.29 & 0.03 \\
DM intake, $\mathrm{kg} / \mathrm{d}$ & 1.36 & 1.30 & 0.05 \\
Feed efficiency $^{1}$ & 5.1 & 5.02 & \\
\hline
\end{tabular}

${ }^{\#} \mathrm{~A}=$ Control diet (without wheat bran), $\mathrm{B}=$ Treatment diet (wheat bran treated diet)

${ }^{1}=\mathrm{kg}$ feed per pen $/ \mathrm{kg}$ gain per pen

The second experiment i.e. Trial 2 was conducted to study the effects of wheat bran on finishing lambs when supplemented at different levels to a corn diet (Table 2). Wheat bran, in many instances, has the advantage over corn of digestible fiber rather than starch (as in corn) and, therefore, supplements energy while minimizing changes in ruminal fermentation (Anderson et al., 1988). Growth data and feed intake by different groups are summarized in Table 4. Results indicated that average daily gain (ADG) was highest in $A$ (control) compared to other treatments. Average daily gain in B (22\% wheat bran) was $0.25 \mathrm{~kg}$. This gain less than $A$ (control), but higher than $C$ and $D(46 \%$ and $68 \%$ wheat bran, respectively). It is evident that B group (22\% wheat bran) maintained their body weight during the trial, whereas, the animals lost weight in $C$ (46\% wheat bran) and $D(68 \%$ wheat bran). The negative response in $C$ and $D$ (Table 4 ) indicated that lambs lost weight on average $0.54 \mathrm{~kg}$ and $1.23 \mathrm{~kg}$ per day, respectively. A t-test indicated that control group (no wheat bran supplement) was significantly different from those on wheat bran treated diets $(\alpha=0.05)$. The increased intake with increasing level of energy supplement was higher for $B$ than other diets ( $C$ and $D$ ) suggesting that optimum fiber in the wheat bran contributed more to ruminal fill. Oliveros et al. (1989) suggested that ground corn diets negatively affected fiber utilization whereas corn bran had a less detrimental affect and tended to be highly efficient. Kellems et al. (1989) suggested that bran could be a viable alternative energy source to replace high-priced rolled barley. Animals gained more weight $(P<0.05)$ during the trial period with Holstaien dairy calves than did the controls (without wheat bran) which could be a result of a greater gastrointestinal tract fill. Feeding more wheat bran supplementation (46\% 68\%) in this experiment showed a negative response causing body weight loss and large amounts of refusals. A possible reason is non-adaptation to the wheat bran diet as well as failure to bring change in ruminal fermentation. Digestive disorders were also associated with higher supplementation of wheat bran (68\%). The clinical signs of indigestion were characterized by anorexia, lack of regurgitation reflex, ruminal hypotomia as observed by Lubiarz (1987) when animals received a pelleted diet without 
Bang. J. Anim. Sci. 2009, 38(1\&2)

bran. Klopfenstein et al. (1985) also observed that at a level of 50\% corn bran reduced fiber digestion.

Table 4. Gain parameters of sheep fed increasing level of wheat bran substituted for corn grain in 4 week trial (Experiment 2)

\begin{tabular}{|c|c|c|c|c|c|}
\hline \multirow{2}{*}{ Items } & \multicolumn{4}{|c|}{ Diets $^{\#}$} & \multirow{2}{*}{ SE } \\
\hline & A & B & C & D & \\
\hline Final wt (kg/pen) & 471.80 & 438.0 & 418.15 & 394.30 & 32.05 \\
\hline Initial wt (kg/pen) & 432.26 & 431.82 & 433.17 & 430.89 & 0.94 \\
\hline Gain or Loss (kg/pen) & 39.54 & 6.18 & -15.02 & -34.56 & 31.77 \\
\hline Average feed intake $(\mathrm{kg})$ & 1.51 & 1.63 & 1.48 & 1.16 & 1.13 \\
\hline Feed efficiency ${ }^{1}$ & 8.55 & 59.20 & Neg. & Neg. & - \\
\hline
\end{tabular}

${ }^{\#} \mathrm{~A}=$ Control diet (without wheat bran), $\mathrm{B}=22 \%$ wheat bran supplement diet, $\mathrm{C}=46 \%$ wheat bran supplement diet, $\mathrm{D}=68 \%$ wheat bran supplement diet

$\mathrm{SE}=$ Standard error of the treatment based on 8 lambs per treatment

${ }^{1}=\mathrm{kg}$ feed per pen/kg gain per pen

\section{Literature Cited}

Anderson, S. J., Merrill, J. K., McDonnell, M. L. and Klopfenstein, T. J. 1988. Digestibility and utilization of mechanically processed soybean hulls by lambs and steers. J. Anim. Sci. 66: 2965.

Cheeke, Peter R. 1991. Wheat Milling By-Products. In: Applied Animal Nutrion. Feeds and Feeding. Macmillan Pub. Company. New York. pp. 54.

Fleck, A. T., Lusby K. S., Owens, F. N. and McCollum, F. T. 1988. Effects of corn gluten feed on forage intake, digestibility and ruminal parameters of cattle fed negative grass hay. $\mathrm{J}$. Anim. Sci. 66: 750.

Kellems, R. O., Powell, K. L., Wallentine, M. V., Andrus, D. Romo, G. A. and Jones, R. 1989. Effect of replacing rolled barley with pelleted wheat bran on performance and milk composition of lactating Holstein dairy cows. Proceedings Western Section, American Society of Animal Sci. 40: 407.

Klopfenstein, T. K., Goedeken, F. K., Brandt, R. T., Britton, R. and Nelson, M. L. 1985. Corn bran as high fiber energy supplement. Nebraska Beef Cattle Rep. MP 48: 49.

Lubiarz, J. 1987. Indigestion syndrome in beef cattle: some clinical and biochemical alterations due to the diet. Bulletin of the Vet. Inst.in Pulway. 30-31: (1-4)83-90.

Morrison, B. F. 1961. The other cereals and by-products. In Feeds and Feeding. $9^{\text {th }}$ Ed. The Morrison Publishing Company, Clinton, lowa.

NRC. 1985. Nutrient Requirements of Sheep. National Academy Press, Washington, DC.

Oliveros, B. H., Klopfenstein, T. J., Goedeken, F. K., Nelson, M. L. and Hawkins, E. E. 1989. Corn fiber as an energy supplement in high roughage diets fed to steers and lambs. J. Anim. Sci. 67: 1784.

Ott, Layman. 1984. An Introduction to Statistical Methods and Data Analysis, $2^{\text {nd }}$ Ed. Duxbury Press, Boston.

Patience, J. F., Young, L. G. and McMillan, I. 1977. Utilization of wheat shorts in swine diets. J. Anim. Sci. 45: 1294.

Preston, R. L. 2006. '2006 FEED COMPOSITION TABLES.' www.Beefmagazine.com. (Access on February 5, 2010)

SAS. 1988. SAS User's Guide: Statistics. SAS Inst., Inc., Cary, NC. 